2821.1 $\mathrm{S} 15 \mathrm{~B} 6 \mathrm{X}$ SOA 



\section{LAS RUINAS DE TINTI}

EN EL VALLE DE LERMA (PROVINCIA DE SALTA)

POR

ERIC BOMAN

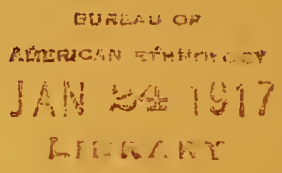

EDICION DEL' $\triangle$ TTOR

BUENOS AIRES

IMPRENTA DE CONI HERMANOS

684 - CALLE PERÚ - 684

\section{6}

(Apareció ol 11 de diciembre) 

IYLLES DEL HUSEO NACIOYAL IJE IISTORIA NATURAL DE BULNOS MIRES To) MO Xxvil, PÁG. 521 ^540

\section{LAS RUINAS DE TINTI}

EN EL VALLE DE LERMA (PROVINGIA DE SALTA)

POR

ERIC BOMAN

EDICIÓN DEL AUTOR

BUENOS AIRES

IMPLENTA DE CONI HERMANUS

684 - CALLK PERÚ - 684

1916

(A praterio ol 11 de dicientse) 


$$
\begin{aligned}
& F(2821 ! \\
& 51507
\end{aligned}
$$




\title{
LAS RUINAS DE TINTI EN EL VALLE DE LERMA
}

\author{
(PROVINCIA DE SALTA)
}

POR

ERIC BOMAN

En 1903 efectné, como miembro de nna misión científica enviada por el Ministerio de Instrucción Pública y Bellas Artes de Francia, investigaciones arqueológicas en el Valle de Lerma. Visité entonces las ruinas del pueblo prehispánico de Tinti, pero no me fué posible permanecer allí más que un día, durante el cual pude estudiar estas ruinas en sus rasgos generales, levantar plano de una de sus viviendas típicas y practicar varias excavaciones en los curiosos sepulcros del pneblo, las que dieron nu resultado poco satisfactorio a cansa del deterioro que habían sufrido los esqueletos y alfarería funeraria por la humedad y acción del tiempo. No pude conseguir completa sino una pequeña escudilla de tierra cocida. Mis investigaciones en Tinti se hallan publicadas en mi obra general sobre las antigiiedarles de la región andina de la República Argentina '.

En 1912 el naturalista riajero del Mnseo Nacional de Historia Natural de Buenos Aires, don Enrique de Carles, realizó excavaciones en Tinti durante una semana y logró extraer de los sepulcros nu número bastante considerable de piezas más o menos completas, así como un cráneo entero. Siendo bastante raro encontrarse con series de objetos arqueológicos del noroeste argentino acompanados de datos anténticos sobre su procedencia, ereo interesante la publicación de la

1 Enc Boman, Antiquités de la région andine de la République Argentine et du désert d'Atacama, tomo 1, páginas 311-314. París, 1908. 
colección del señor de Carles, $y$, antes de proceder a su descripción, reproduciré mis propias observaciones hechas en el lugar.

Tinti ${ }^{1}$ está situado a mos 35 kilómetros al sudsudoeste de la cindad rle Salta, a más o menos 7 kilómetros al sudoeste del pueblo de Rosario de Lerma y casi a la misma distancia al noroeste de la casa habitación de la hacienda Carbajal.

Las altas y abruptas montañas que encuadran al Valle de Lerma forman allí una especie de rincón. Las ruinas se hallan en una llannra, limitada al sud por estas montañas y al norte por colinas y barraneas que la separan del resto del valle. Un pequeño arroyo, mo de los numerosos tributarios del Río Arias, atraviesa la llanura. No hay más que un acceso fácil a la pequeña llanura de Tinti : al este, doncle sale este arroyo, hacia Carbajal. Por todlos los demás lados las monta. ñs, colinas y barrancas encierran la llanura y deben haber facilitado la defensa de sus habitantes contra las invasiones de los enemigos.

El pueblo prehispánico está situado cerea del arroyo y consta de unas 150 viviendas, compuesta cada una de un recinto cercado grande que está en conexión con varias habitaciones. Cada nno de estos conjuntos debía servir para morada de una familia. Levanté de una de estas viviendas, escogida como típica, el plano figura 1, donde se ven dos habitaciones graudes, de $8 \times 7$ y $9 \times 5$ metros, que se abren sobre $u$ recinto o patio de más o menos $25 \times 16$ metros. Las habitaciones tienen puertas haeia el patio, pero éste no presenta ninguna

1 Tinti, palabra quichna, quiere decir langosta, $\mathrm{y}$ es probable que el nombre de nuestro pueblo prehispánico se derive de esta palabra. Hay una aldea Tinti en el departamento de Cochinoca, provincia de Jujuy, 5 también hay Tintigasta, lugir poblado en el departamento de Santa Rosa (Catamiarca). La misma palabra figura en el nombre de un arbusto del género de los algarrobos, el tintituco (Prosopis: adesmioides Griseb.), común en toda la region andina argentina, $y$ cuyo nombre vulgar se compone de tinti = langosta 5 tacu = algarrobo : "algarrobo de las langostas ». Pero existe igualmente otra palabra quichua, tintin = granadillı, la fruta de varias enredaderas del género Passifore. Esta palabra figura en los nombres Cerro Tintin, en Cachi (Salta), Tintincillo, lugar poblado en el departanzento de San Carlos, de la misma provincia, y Tintiua, estación del Ferrocarril Central Norte, en el norte de Santiago del Estero. Con la actual corrupción del quichna, itloma que sa ha desaparecido en Salta, Catanarea 5 Tuenmán, no sería difícil que hubiera confusión entre las dos palabras citadas, cuando constitusen nombres geográficos. Eu el Perú hay numerosos nombres derivados tanto de tinti cono de tintin. Así Tinti, hacienda en la provincia de Huananga (departamento de Ayacucho), Tintililla (Lneana, Ayacncho), Tintiragra (Pomebamba, Ancachs), Tintin en Asangaro (Pnno), e igualmente en Unión (Arequipa) y eu Carumas (Mloqnegua). 
abertura que comunique con el exterior. Una peqneña muralla que arranca del muro exterior forma, al lado de la pieza situada en el ángulo oeste del patio, un espacio encerrado por tres lados, pero abierto hacia éste. Los muros del recinto continúan hacia el noroeste. En el plano están interrumpidos en los puntos a y $b$, pero signen mucho más lejos y parecen haber continuado hasta la vivienda vecina, for-

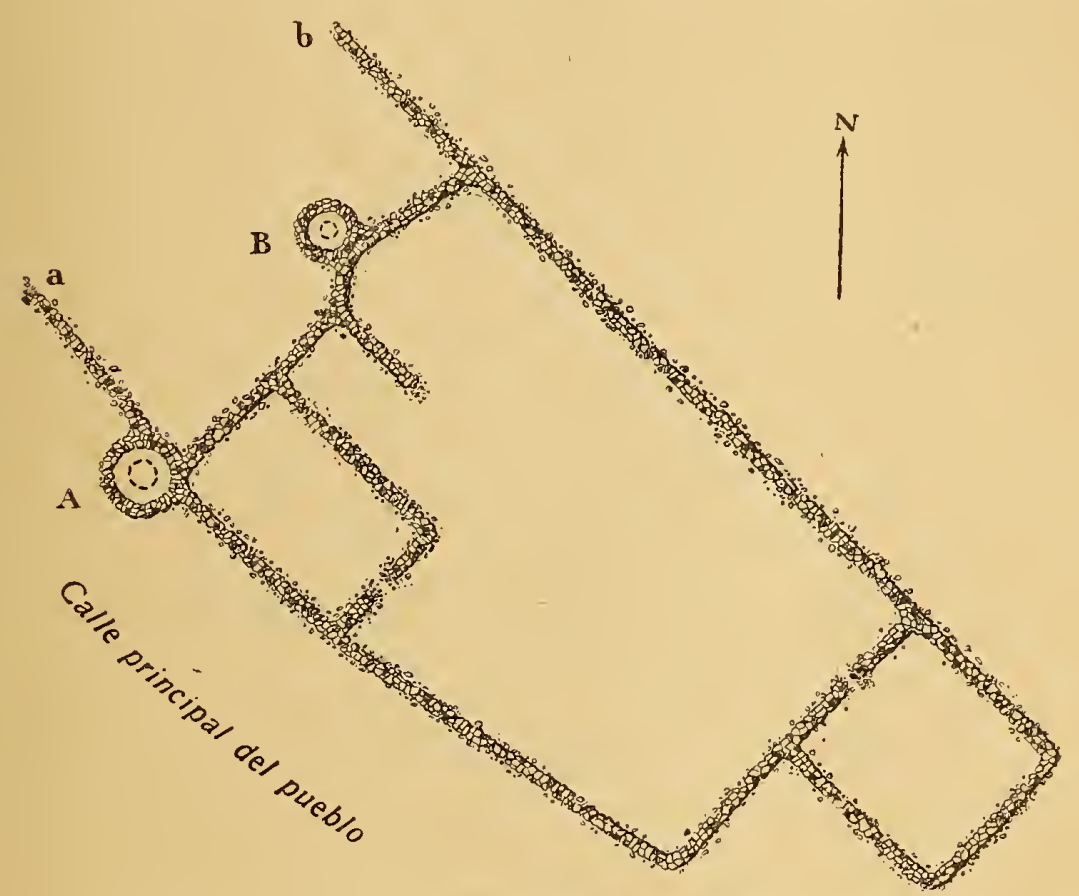

Fig. 1. - TrNтr. Vivienda típica del pneblo prehispánico (escala $1 / 400$ )

mando un gran recinto desprovisto de habitaciones, el que quizás servía para agricultura o para encerrar las llamas que constituían el ganado de los indios.

Los muros o pircas, tanto de las habitaciones como de los grandes reciutos, están construídos sin argamasa, con piedras brutas, la mayor parte rodaclas, procedentes del arroyo vecino. Actualmente alcanzan un poco más de 50 centímetros de alto. Es difícil formar un juicio sobre su ancho primitivo, pues no se distinguen bien las piedras lerrumbadas de las que todavía se encuentran en su lugar en la muralla. Sin embargo se ve que el ancho de ésta ha sido de más de 50 centímetros, pero de menos de un metro. Parece haber tenido un eimiento que no pasa de 50 centímetros de profundidad. 
Estos muros no pueden nunca haber siclo muy altos. El terreno no rontiene piedras del mismo tamaño de las de los muros y las piedras derrnmbadas deben en general haber quedado al pie de los muros de que habían formado parte. En las cercanías no existe ninguna construcción moderna, para la enal se pudieran haber ntilizado las piedras de las ruinas. Por consigniente es fácil calcular la altura originaria de los muros por el número de piedras sueltas que se eneuentran a sus lados, y este é́leulo da como resultado una altnra de más o me. nos nn metro solamente. Esta eircunstancia indnce a suponer que los muros constitnían sólo la parte inferior de las paredes de las habitaciones, siendo sn parte superior eompuesta de un armazón de madera eubierto rle paja o de cueros. El techo debe también haber sido hecho de $u n o$ n otro de esos materiales. Una gran parte de las ruinas del noroeste argentino dan Ingar a reflexiones análogas.

Lo que muy especialmente llama la atención en las ruinas de Tinti son los sepulcros cilíndricos, semisnbterráneos, adjuntos a casi todas las viviendas. En el plano figura 1 se ven dos de estos sepulcros, $A$ y $B$, construídos en pirca, como los muros de las habitaciones y recintos, pero con más prolijidad. Su piso está enbierto de piedras planas y los muros también están revestidos interiormente con piedras planas que forman un eilidro interior en el cual se hallan los cadáveres. Este cilindro está enbierto eon nna piedra plana. Los eilindros interiores tienen unos 70 centímetros de altura; el diámetro interior del sepulcro $A$ es de un metro y el del sepulero $B$ de 65 centímetros. Las piedras planas que sin ven de tapas a las sepulturas están a algunos centímetros sobre el nivel del suelo, y el muro cilíndrieo lo sobrepasa en unos 30 centímetros. El sepulcro $A$ contenía dos esqueletos y el $B$ uno solo, pero tan mal conservados que los huesos se deshacían en polvo al tocarlos, lo que ignalmente sucedía en otros sepnleros de la mismar clase, que cavé. Se podía constatar que los carláveres habían sidlo enterrados en posición sentada. En los sepuleros había numerosos fragmentos de pequeños platos y eseudillas, seguramente depositarlos allí con alimentos para los muertos. Como las tumbas se encontraban intactas, estos vasos sin duda habían sido rotos por la presión de la tierra.

Una calle prineipal, ancha, formando amplia curva, atraviesa el pueblo de Tinti. De un lado y otro de esta ealle se enenentra nna fila casi ininterrumpirla de viviendas y recintos semejantes a la construcción que acabo de describir. Tras estas filas hay muchas otras viviendas parecidas, situadas a alguna distaneia unas de otras, 
mientras que las con frente a la calle principal casi se tocan. Todas estas viviendas presentan habitaciones análogas, agruparlas generalmente en número de tres o cuatro alrededor de un recinto o patio común, de forma más o menos cuadrangular. Casi todas tienen agregados sepulcros cilíndricos de la misma construcción y aproximada mente de las mismas dimensiones que los ya descriptos.

El señor de Carles excavó unos quince de estos sepulcros y practicó también algunas excavaciones en el suelo de las habitaciones, no dando estas últimas ningún resultado, de manera que su colección proviene exclusivamente de las construcciones sepulcrales cilíndricas. Algunas de ellas contenían los restos de un cadáver solo, otras dos o hasta tres cadáveres pero en ningún caso más. Como sucedió en mis propias excavaciones en Tinti, los esqueletos se desmenuzaron al contacto con el aire exterior, siendo el señor de Carles sin embargo más feliz que yo, pues pudo recoger un cráneo casi íntegro (lámina XVI), el que después ha podido ser restaurado.

En cuanto al ajuar fúnebre, la colección comprende :

30 piezas de alfarería, inclnyendo algunos fragmentos. La mayor parte consiste en pequeñas escudillas, de las que los paisanos de las provincias del norte denominan con el término quichua puco. De éstas, había una, dos o hasta tres en cada sepulcro. Ocho de estas escudillas están figuradas en la lámina $\mathrm{X} I V$.

Una urna finneraria (figura 2), del tipo de las que en gran número se han encontrado, conteniendo esqueletos de párvulos, en el Valle de Yocavil, sud del Valle Calchaquí y en Pampa Grande (departamento de Guachipas, Salta). Esta nrna ha sido depositada incompleta y ya fragmentada en el sepulcro, como lo veremos más adelante.

Dos asas de urnas de la misma clase de la anterior.

Un fragmento de vaso con ornamentación pintada lámina $X I V h$.

Tres placas de cobre figura 3 .

Un pequeño disco de piedra esqnistosa, grabado, figura 4 .

Dos trozos de obsidiana.

Un trozo de ocre amarillo.

Aunque el señor de Carles no haya levantado plano de los sepulcros excavados ni individualizado los hallazgos según los diferentes sepulcros donde han sido hechos, y a pesar de la sencillez de las piezas, la colección es muy interesante, pues es bastante numerosa para dar una idea general del arte de la alfarería de Tinti y establecer comparaciones que permiten, por decirlo así, identificar a los antiguos habitantes de este preblo prehíspánico y establecer sus afinidades con las tribus que antes de la conquista poblaron los valles de Salta. 
He podido elasificar la alfarería de Tinti, según su pasta y técnica de fabricación, en cinco categorías o tipos distintos que en la descripción que sigue designaré con letras griegas. Prefiero emplear aquí esta clasificación en vez de cualquier otra, pues la preseneia de un número considerable de ejemplares de cada tipo demuestra que los objetos han sido fabricados en el lugar mismo y no traílos de afnera. El tipo $\alpha$ es especialmente sugerente a este respecto, pues si la urua figura 2 y las grandes vasijas lámina $X V$ no fuesen de la misma pasta y técnica que las numerosas escudillas de este tipo, estaría uno tentado de sospechar un origen extraño a esas piezas.

\section{ALFARERÍA TIPO $x$}

Pasta roja, de un color ladrillo vivo, homogénea, bien cocida. Presenta una pátina color gris ceniza que se puede sacar raspándola con una punta de acero, después de humedecerla. Es la primera vez que he observado esta clase de pátina en la alfarería de la región andina. Sin duda ha sido aplicada intencionalmente a la alfarería roja, para darle el color gris que probablemente agradaba a los alfareros y sus clientes. El procedimiento debe haber sido éste : sacadas las piezas del horno u hoguera donde habían sido cocidas, y todaría calientes, han sido pintadas con arcilla fina, gris, dilnída (à la barbotine). Así la capa de arcilla ha quedado en estado casi crudo, y por eso es relativamente fácil rasparla. El procedimiento es, segín lo que yo sepa, especial para Tinti.

Esta categoría está representada por las piezas más numerosas de la colección. A ella pertenecen las escudillas lámina $X I V, c, d, f$, de 26,19 \% y 19 centímetros de diámetro máximo, respectivamente, y además otras seis escudillas, de formas parecidas y del mismo tamaño o un poco menores. Cuatro de éstas tienen asas en forma de herraclura, iguales a las que se ven en los ejemplares a e $i$ de la lámina.

Al mismo tipo de alfarería * pertenece también la urna finneraria figura 2, de 51 centímetros de altura y de sección ovalada. Como ya hemos dicho, esta urna fué encontrada en tuno de los sepulcros cilíndricos, rota en muchos pedazos e incompleta, como se ve en la figura. Fuera de la parte que allí aparece ausente, faltan también grandes trozos del lado opnesto de la mrna. Es seguro que ha sido depositada en estado ya incompleto y es probable que haya caíclo en pedazos al depositarse. Algmos de los trozos con que ha sido reconstrú́cla pre- 
sentan la particularidad de que han perdido la pátina gris por haber estarlo en la tierra en una posición que los ha expuesto especialmente a la humedad y otros agentes que destruyeron la pátina en estos pedazos. Así, la urna restanrada presenta un aspecto raro: gris en su mayor parte, pero con algunos trozos de color rojo vivo. Y las rotu-

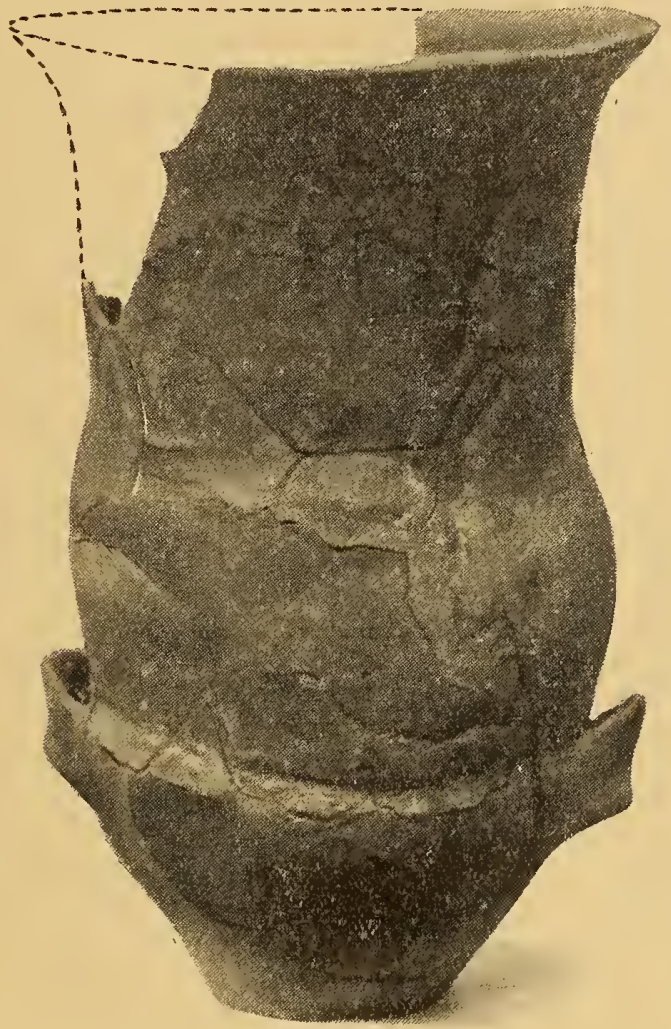

Fig. 2. - Urna funeraria $(1 / 5$ del nat.)

ras corresponden perfectamente entre sí, de manera que no hay duda ninguna sobre el lngar que ocmpan los distintos trozos en la formación de la vasija entera. Urnas exactamente de la misma forma han sido encontradas por Juan B. Ambrosetti en Pampa Grande ' y en La Paya ", solamente que estas urnas están decoradas con ornamentos pin-

1 J. B. Ambrosetti, Exploraciones arqueológicas en la Pampa Grande (provincia de Salta). Facultad de Filosofía y Letras, publicaeiones de la Sección Antropológiea, Número 1, página 26. Buenos Aires, 1906.

2 J. B. Ambrosetri, Exploraciones aqueológicas en la ciudad prehistórica de La 
tados y en relieve, de los que carece la nuestra. Las uruas de la mis. ma forma y ornamentación soll comunes en los cementerios prehistóricos de párvulos del departamento de Santa María, en Catamarca, y valles adyacentes. Del Valle de Lerma no conozco sino un ejemplar ile esta clase de urnas, el cual desenterré cerca de Pucará de Lerma ', a unos 12 kilómetros al norte de Tinti. Tenía rastros de ornamentación pintada y se parece por sus dobles asas a ciertas urnas de Pampa Grancle. Que la urna arriba descrita no ha siclo única en Tinti, lo demuestran dos asus de urnas de la misma forma y de la misma técmica alfarera, encontradas en otros sepulcros.

Finalmente pertenecen al tipo $\alpha$ las dos enormes vasijas lámina $X V$ que describiremos más adelante.

\section{ALFARERTA TIPO $\beta$}

Tierra menos pura que la categoría anterior. Alfarería muy bien cocida, más dura que la del tipo $\alpha$. Carece de la pátina gris de este tipo.

Aquí pertenecen las escudillas lámina $X I V, a, i$ y otra no figurada. La escudilla $i$ está pintada interiormente en rojo a frío con arcilla de la clase que los alfareros franceses llaman terre de foulon.

Hay una pequeña escudilla intermedia entre los tipos $\alpha$ y $\beta$. Por la pasta y cocción se parece al último tipo, pero presenta interiormente la pátina gris del tipo $\%$, mientras que exteriormente está engobada en rojo obscuro y bien pulida.

\section{ALFARERÍA TIPO $\curlyvee$}

Tierra diferente a las dos clases anteriores. Alfarería de un rojo vivo claro, de mucho menor consistencia que éstas; se rlesmenuza con facilidad con un cepillo común. Dos de las piezas tienen ornamentos pintados en negro sobre cocido.

Son de esta clase las escudillas limina $\mathrm{T} 1 \mathrm{~V}, b, g, e(24,11$ y 14 centímetros de diámetro de abertura respectivamente) y tres más de la misma forma del último y 14 a 16 centímetros de diámetro.

La escudilla $b$ está decorada exteriormente con tres filas de nean-

Paya (Talle Calchaqui, provincia de Salta). Facultad de Filosofía y Letras, publicaciones de la Sección Antropológica, Número 3, página 110. Buenos Aires, 1907.

1 E. Bomax, Antiquités cit., tomo I, páginas 294-295, lámina XVII, figura 41. 
dros reunidos por escaleras, pintados en negro sobre el fondo rojo deI vaso. Esta ornamentación es común en la región diaguita. Es curioso que en Tinti se encuentre aisladamente una pieza así adornada, entre tantas otras sin ornamentos. Lo mismo me sucedió en el gran pueblo prehispánico de Tastil, en la Quebrada del Toro, en cnyos sepulcros encontré, entre mucha alfarería sin ornamentación pintada, dos pequeñas vasijas decoradas con meandros ${ }^{1}$. En cuanto a la pintura de Ia pieza en cuestión, puede ser que haya sido hecha con negro de humo dilú́do junto con una materia mucilaginosa, por ejemplo jugo de cactus, que sirviera como mordiente.

La pequeña escudilla $g$, de la misma alfarería fácilmente desmenuzable, no tiene pintura ninguna, pero está ornada con dos pequeñas asas dirigidas hacia arriba, de una forma bastante común en toda la región andina de la Argentina.

La escudilla $e$, también de alfarería tipo $\%$, está como las tres piezas no figuradas, engobada exteriormente con terre de foulon, dilnída con mordiente y aplicada antes de la cocción, mientras la pieza todavía estaba hímeda. Este engobe bien pulido, da un aspecto brillante, de rojo obscuro, a las vasijas, y debe también haber contribuído a la impermeabilidad de las mismas.

El fragmento lámina $X I V h$, es de la misma clase de alfarería que las piezas precedentes. Debe haber pertenecido al borde de un vaso de unos 30 centímetros de altura, con boca ancha y borde abierto hacia afuera. Fué hallado en el interior de la gran vasija lámina $X V$ D. La decoración pintada es tan selleilla como original. La capa de pintura negra en este fragmento es mucho más delgada que la de la escudilla lámina $X I V b$. El color empleado muy posiblemente ha sido un jugo vegetal, pues aplicando negro de humo, tierras o substancias grasas o resinosas no se podría haber formado una capa tan delgada ni contornos tan netamente definidos como los de los ornamentos del fragmento en cuestión. Hablando con el distinguido escultor Américo Bonetti, muy conocedor de la técnica alfarera indígena del Paraguay, me manifestó que allí se emplea para formar figuras negras sobre los vasos el jugo de la fruta del ñandypá (Sorocea ilicifolia Miq.). Es posible que también en la región diaguita se hayan empleado para este objeto colores vegetales. EI estudio de esta cuestión es sumamente interesante, pues con razón llama la atención esa pintura tan resistente a la acción del tiempo que se ve sobre las vasijas prehispánicas de la región andina argentina.

1 E. Bonan, Antiquités cit., tomo I, página 375 y lámina XXXI, figura 83. 


\section{ALFARERÍA 'NIPO う}

Comprende una sola escudilla sencilla, pequeña, sin asas, de pasta color gris, y engobada exteriormente con tierra grasa, plomiza, bien pulida, lustrosa.

\section{ALFARERÍA TIPO ミ}

Fragmentos de alfarería rloméstica, de pasta gris grosera, mal cocida. Hay un fondo de una vasija grande, un sector de una escudilla cónica, un pequeño vaso grosero de 10 centímetros de diámetro y otro fragimento. El último y también la escudilla cónica presentan en la superficie las mismas estrías que se ven en lá gran vasija lámina $X V^{\top} D^{\prime}$. Estos fragmentos probablemente han sido tirados en las sepulturas por castalidid o como soportes o tapas de algún objeto o raso.

Las tres placas de cobre halladas en los sepulcros de Tinti están reproducidas en la figura 3 . Tienen algo más de un milímetro de espesor y están regularmente oxidadas. La placa $a$ es rectangular con las esquinas redondeadas. Presenta un agujero asimétrico que no parece hecho con puinzón, sino que tal vez sea debido a alguna influencia química que ha sufrido la pieza en la tierra. El agujero de suspensión, en el borde superior, está solamente indicado por una pequeña abolladura, producida por el punzón al empezar la perforación, la que no se ha llevado a término. La placa $b$ afecta la forma de un segmento de círculo, pero éste ha sido trazado a ojo, no correspondiendo la línea curva ni a un círculo perfecto, ni a una elipse, parábola o cualquier otra figura curvilínea geométrica. La placa tiene dos agujeros de suspensión, formados, como el de la placa siguiente, con punzón. Un extremo de la pieza está destruído por la oxidación. La placa $c$ tiene la forma de cuadrilátero irregular, y ha tenido esta forma originariamente, pues los bordes no han sido tocados por la oxidación. Los bordes inferiores de estas placas son cortantes, intencionalmente afilados, de manera que es probable que las piezas, fuera de su objeto como adorno, hayan sido utilizadas también como instrumentos cortantes.

Por deferencia del director de la Casa de Moneda de Buenos Aires, ingeniero Alfrerlo J. Orfila, el metal de la placa $c$ ha sido analizado 


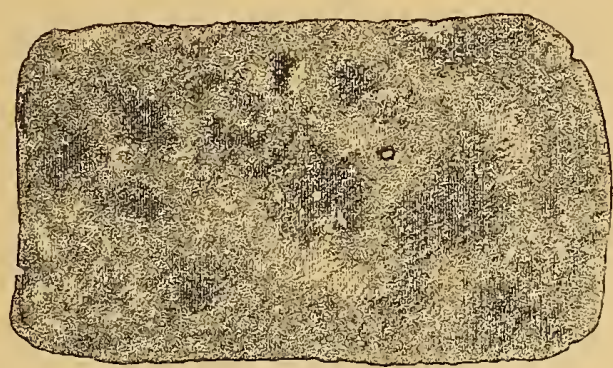

a
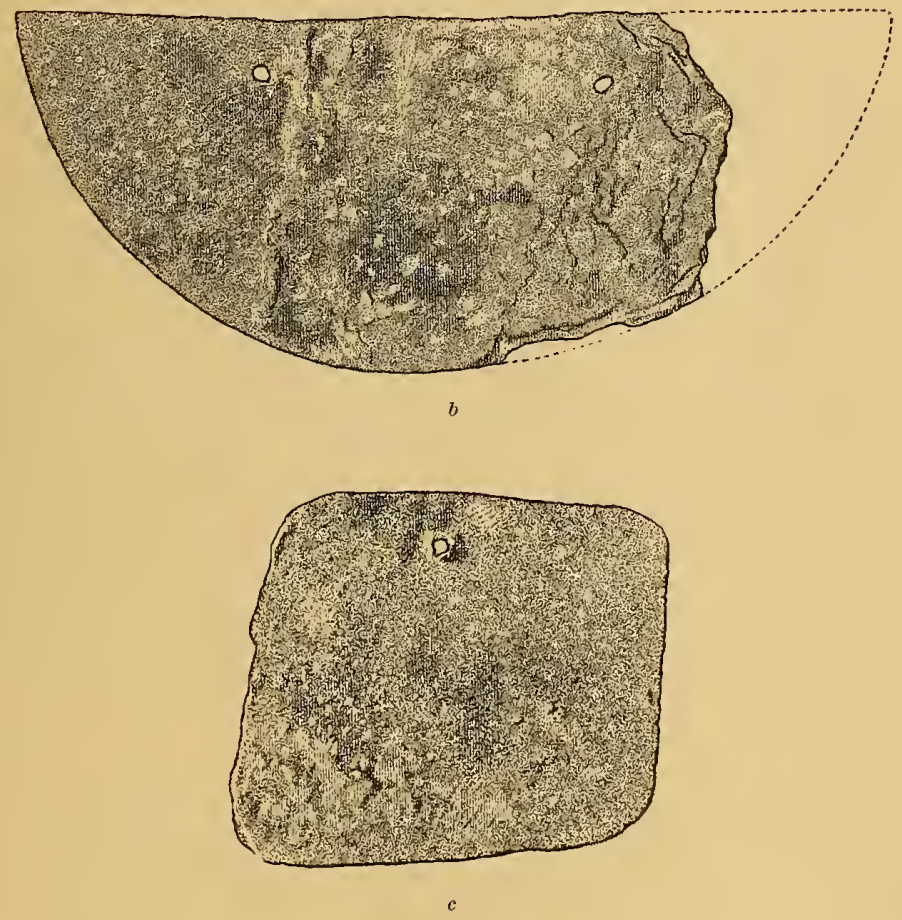

Fig. 3. - Placas de colre $(1 / 3$ del nat.) 
por el jefe del laboratorio de dicho establecimiento, dloctor Jacinto T. Raffo. El análisis ha dado el siguiente resultado:

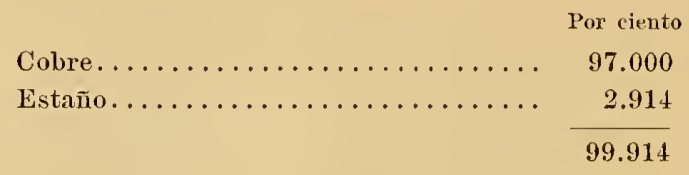

El bajo porcentaje del estaño corresponde perfectamente a la generalidad de los objetos de la misma aleación, procedentes de la región diaguita.

El pequeño disco, figura 4, es de esquisto arcilloso color verde claro, de 3 centímetros de diámetro por 4 milímetros de espesor, y su agujero central de 4 milímetros de diámetro. A pesar de su peso exí-

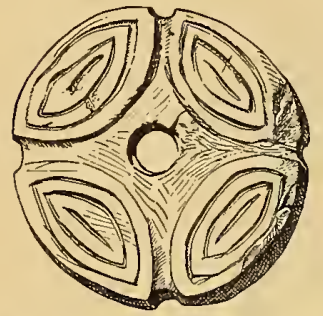

Fig. 4. - Disco de esquisto arcilloso, probablemente un tortero (tam, nat.). guo $(7 \%$ gramos $)$ me inclino a creer que se trata de un tortero de huso; sinó, sería un objeto de arlorno. Ambrosetti ${ }^{1}$ publica de sus excavaciones de La Paya numerosos objetos de madera, más o menos del mismo tamaño y de la misma ornamentación, y el autor de la presente memoria ${ }^{2}$ también ha exhumado en las ruinas de los pueblos prehistóricos de Morohuasi y Tastil, en la Quebrada del Toro, objetos semejantes, igualmente de madera.

Los dos fragmentos de obsidiana encontrados en los sepulcros de Tinti, se componen de un núcleo muy gastado y una lasca ${ }^{3}$ de 3 centímetros de largo. El hallazgo es interesante, pues demuestra que los habitantes de este pueblo fabricaban puntas rle flecha de este material, aunque ni yo, ni el señor de Carles hemos hallado ninguna.

1 J. B. Ambrosetri, La Paya cit., páginas 12, 105, 129, 463.

$\approx$ E. Boman, Antiquités cit., tomo I, páginas 342,373 , figura 56 đ $\mathrm{y}$ lámina XXVII, figura $75 i$.

${ }^{3}$ Empleo este palabra por éclat, según la Nomenclatura de voces técnicas y de instrunentos típicos del Paieolítico, formulada por la Comisión de Investigaciones Paleontológicas y Prehistóricas de España, en su Memoria nímero 10 (Madrid, Museo Nacional de Ciencias Naturales, 1916). Los términos de dicha nomenclatura están en general bien elegidos, y annque ciertas denominaciones francesas hayan presentado graudes dificultades, como coup de poing que la comisión traduce por hacha de mano, debemos agradecer este eusayo de dotar al castellano de una terminología científica de que carecía. 
Puntas de flechas de obsidiana son comunes en un gran número de localidades prehistóricas de toda la región andina argentina, pero llama la atención que en la literatura geológica no se halla ningún dato sobre yacimientos naturales de este mineral, de donde los indios pudieran haber sacado la materia prima para sus flechas. La única información que he podido obtener al respecto proviene del doctor Pablo Groeber, geólogo de la Dirección General de Ninas y Geología, quien ha encontrado masas de obsidiana in situ, como roca, en la Cordillera, cerca de la Lagnna del Maule, sobre el límite de la provincia de Mendoza, territorio del Neuquen y república de Chile, es decir, ell una región situada completamente fnera de la ocupada por la civilización andina prehispánica argentina. Más al norte, en las cercanías del Río Grande, en el sur de la provincia de Mendoza, el doctor Franco Pastore, ignalmente geólogo de dicha repartición, ha encontrado en el snelo arenoso dos pequeñas lascas de obsidiana que no podían haber sido llevadas allí por unanos de hombre. En el museo mineralógico de la Dirección General de Minas y Geología no existe sinó una muestra de obsidiana, procedente del Salar de Caurchari, en el territorio de Los Andes. La obsidiana es un producto de erupeiones volcánicas de materiales muy ácidos, $y$, segín tuvo a bien comunicarme el doctor Pastore, el territorio de Los Andes constituye jnstamente la zona principal de volcanes ácidos, annque allí no se haya encontrado nunca la obsidiana in situ, sinó solamente en fragmentos sueltos, quebrados. Sin embargo, esto no excluye la posibilidad de que existieran yacimientos en las partes de la Cordillera pertenecientes a Catamarea, La Rioja y San Juan. El problema es interesante. pues con un conocimiento exacto de los yacimientos podríamos dedncir, si los indios prehispánicos han buscado este material, para ellos precioso, en las mismas comarcas que habitaban, o si la obsidiana ha sido un artícnlo de intercambio comercial entre regiones lejanas.

El ocre amarillo, hallado en nna sepultura, forma una masa redondearla de unos $4 \times 3$ centímetros, es de estructura mny fina y tiñe inmediatamente los dedos al tocarlo. Ha servido probablemente para pintar la cara o el cuerpo.

Pasaremos ahora a un descubrimiento muy curioso que hizo el señor de Carles. En el límite del pueblo, un poco afnera de las casas, encontró dos construcciones subterráneas cilíndricas, parecidas a las construcciones sepulcrales anexas a las habitaciones antes descritas. pero mucho más grandes, designadas con las letras $C$ y $I$ ) en el cro- 
"guis figure 5 '. A poca distancia de estas construeciones había dos piedras, $e$ y $f$, paradas en el snelo, de unos 80 centímetros cle altura sobre el mismo y de sección casi rectangnlar, $30 \times 20$ centímetros. Estas piedras se encontraban a más o menos 7 metros de distancia una de otra, y puede decirse que formaban una especie de «puerta de entrada» al pueblo.

La construcción $D$ tiene unos 3 metros de diámetro exterior, la $C$ un poco menos. Las murallas, más gruesas que las de los sepulcros comunes, alcanzaban a mos 80 centímetros de profundidad, bajo tierra, y sobresalían de ésta umos treinta centímetros. No había piso ning'mo, ni revestimiento interior de piedras lajas.

Estas dos construcciones no contenían restos humanos ninguno,

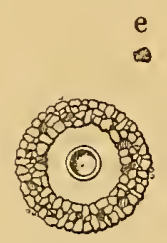

C f

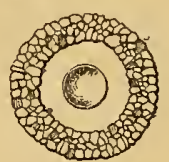

D

Fig. 5, - Gramles construcciones cilindricas, análogas a los sepuleros del preblo (escala $1 / 200$ )

pero sí dos evormes tinajas reproducidas en la lémina $\mathrm{X} V \mathrm{C}$ y $D$, teniendo la primera 70 centímetros de diámetro de lá panza y 46 centímetros de altnra. La tinaja $D$ no es perfectamente redonda; el diámetro de su boca varía entre 91 y 96 centímetros, siendo su altura de $t 1$ centímetros. Las paredes son de un centímetro de grneso en la $C$ y de un centímetro y medio en la $D$, anmentando el espesor de ambas tinajas hacia el fondo. Son de alfarería roja, de pasta un poco más grosera que las pequeñas escndillas de nuestro tipo $x$, pero presentan la misma pútina que las clemás piezas rle este tipo. El alisamiento de estas enormes piezas se ha hecho con un útil provisto de dientes finos, como lo demnestra la parte de la superficie interior de la timaja más grande, representada en la lámina $X V D^{\prime}$, viéndose claramente en la fotografía las estrías dejadas por dicho instrumento. He observado la superficie estriada de la misma manera en otras piezas grandes, antes desenterradas por mí en la Qnebrada del Toro y Valle de Lerma.

Estos dos enormes vasos, como hemos dicho, no contenían restos

1 Este croquis ha sido confeccionado según los datos del señor de Carles. 
bumanos ninguno: la $C$ éstaba vacía y en la $D$ se hallaban dos de las pequeñas escudillas sin ornamentación pintada, arriba descritas, así como también el fragmento pintado lámina XIVh.

- Qué destino pueden haber tenido estas construcciones sepulcrales que no son sepulcros? Depósitos de víveres u otros objetos no pueden haber sido. La hipótesis más probable es que han sido destinadas a un fin religioso. Probablemente se depositaban en las grandes vasijas que contenían, ofrendas a alguna deidad. Las escudillas halladas en una de ellas parecen corroborar esta hipótesis.

El cráneo que logró el señor de Carles extraer de uno de los sepulcros de Tinti casi completo, aunque fragmentado, está reproducido en cuatro normas en la lámina $X V I$. Presenta la deformación intencional fronto-occipital, tan común en la región andina, pero en este caso poco pronunciada. Ha sufrido arlemás una deformación póstuma que ha determinado una plagiocefalía relativamente marcada. Por otra parte, no han podido evitarse ciertas pequeñas irregularidades procedentes de la restauración, aunque ésta ha sido efectuada con el mayor cuidado.

Es un cránen masculino, de un individuo de edad madura, ultrabraqui-hipsi-tapeinocéfalo, mesoprosopo, leptorrino. Doy aquí sus medirlas, de conformirlad con las reglas adoptadas por el Congreso Internacional de Antropología y Arqueología Prehistóricas, en su

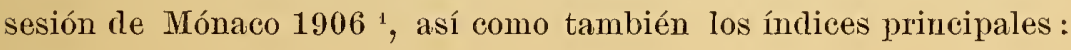

\section{CRÁNEO}

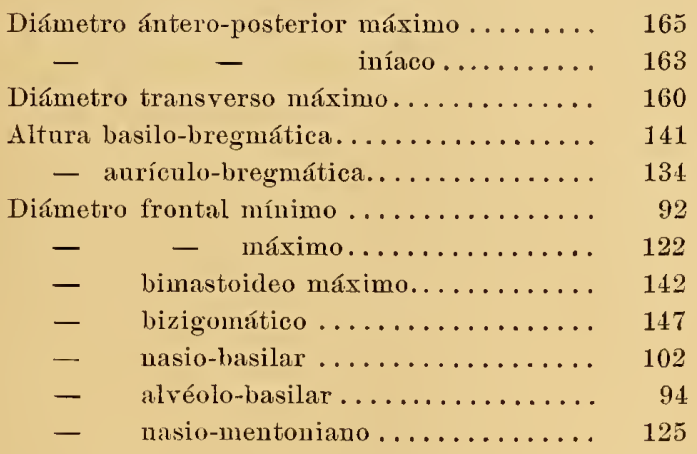

${ }^{1}$ Entente internationale pour l'unificacion des mesures craniométriques ct cephalométriques, en Congrès international d'anthropologie et d'archéologie préhistoriques ; Compte rendu de la treizième session, tomo II, páginas 387-394. Monaco, 1906. 
Diámetro nasio-rlveolar............ 73

Altma nasal................... 52

A ucho nasal..................... 23

- interorbitario............... -

- orbitario.................. 41

Altura orbitaria ................. 36

Ancho del borde alveolar superior ........ 58

Altura de la curva alveolar ............ -

Largo de la hóveda palatina ............ 51

Ancho de la boveda palatina ........... 34

Altura órbito-alveolar ................ 41

Largo del forámen occipital. . . . . . . . . 35

Aucho del forámen oceipital .......... 27

Curva sagital sección frontal.......... 125

- $\quad$ sección parietal.......... 118

- - sección occipital ......... 114

- $\quad-\quad$ total................ 357

- transversal. . . . . . . . . . . . . . . 339

- horizontal.................... 510

Peso del cráneo (sin mandíbula) gramos.... 527

\section{MANDÍBULA}

Ancho bieondíleo ................. 135

- bigoníaco.................. 107

Largo de la rama ascendente........... 65

Aucho mínimo de la rama ascendente ...... 35

- máxino de la rama ascendente..... -

Altura $\operatorname{sinfisiaua...\ldots \ldots \ldots \ldots \ldots \ldots .\ldots ..........~}$

- del cnerpo mandibnlar.......... 35

Espesor máximo del enerpo nandibular .... 17

Ángulo mandibnlar, grados ............ 108

Peso de la mandíbula, gramos........... 98

\section{INDICES}

Longitudino-transversal. ............

Longitudino-vertical..................

Transverso-vertical .............. 88.13

Facial total ................... 85.03

Orbitario ..................... 87.80

Nasal ......................... 44.23

Palatino ....................... 66.67

Si en las regiones circunvecinas buscamos analogías para con las ruimas de Tinti y los lrallazgos hechos allí, las encontramos expecialmente en la parte norte del Valle Calchaqní y en la Quebrada del Toro. 
La sencillez y ausencia general de adornos pintados de la alfarería recuerdan la de los pueblos prehispánicos que he estudiado en la Quebrada del Toro. Las formas de las escudillas son parecidas a las que he descrito de Morohuasi ${ }^{1} \mathrm{y}$ otros sitios de esta quebrada, e igualmente a las descritas por Ambrosetti ${ }^{2}$ de La Paya y por J. A. Dillenius ${ }^{3}$ (actualmente señora de Lehmann-Nitsche) de La Poma, en el Valle Calchaquí. También las mismas formas de asas se han encontrado en todas las localidades citarlas, hecho que merece mencionarse, aunque se trata de formas observadas en otras regiones.

La alfarería de Tinti como la del norte del Valle Calchaquí, la Quebrada del Toro y la Puna de Jujuy carecen de la rica ornamentación tan propia al arte diaguita, aunque ésta no ha dejado de hacer sentir ocasionalmente su influencia en Tinti de lo que nos da un ejemplo la urna figura 2 que es una imitación local de las urnas funerarias del tipo Santa María. La decoráción con meandros de la escudilla lámina $X l V b$ es tal vez también ur ensayo de imitación del arte diaguita o quizís se trata de una pieza importada, lo que probablemente también debe ser el caso del fragmento límina $X I V h$.

En cuanto al pequeño disco o tortero figu' 4 , constituye por su ornamentación un objeto muy sugerente en apoyo de la afinidad de la cultura material de Tinti con la de las regiones mencionadas.

Es cierto que las construcciones y especialmente los sepulcros cilíndricos de Tinti son propios de este pueblo, pero esta circunstancia no puede ser una objeción contra la afinidad en cuestión, pues los tres pueblos prehispánicos de la Quebrada del Toro estudiados por mí, Morohuasi, Puerta de Tastil y Tastil, presentaban notables diferencias en sus construcciones y sepnlturas, y sin embargo como lo he demostrado ", proceden evidentemente del mismo pueblo y de la misma época.

Las investigaciones arqueológicas llevadas a cabo durante los últimos años, por diferentes antores, nos ponen pues en presencia de una cultura distinta de la diaguita, y cuyos restos han sido encontrados en la parte septentrional del Valle Calchaquí, desde La Paya al norte, en la Quebrada del Toro y en el Valle de Lerma, extendiéndo-

' E. Bonan, Antiquités eit., tomo I, página 339 y lámina XXIV, figura 71.

2 J. B. Aмbrosétт, La Paya cit., páginas 323, $306 \mathrm{y}$ figuras 67, 148.

${ }^{3} \mathrm{~J}$. A. Drllenrus, Obsertaciones arqueológicas sobre alfarería funeraria de La Poma (Valle Calchaquí, Provincia de Salta). Facultad de Filosofía y Letras, publicaciones de la Sección Antropológica, Nómero 5. Buenos Aires, 1909.

'E. Boman, Antiquités cit., tomo 1, páginas 380-381. 
se probablemente a las quebradas intermedias, como la de Escoipe, la de Las Capillas y parte de la de Guachipas.

Esta región coincide con la que los historiadores de la conquista dan como ocupada entonces por la tribu llamada Pulares, que el P. Lozano ${ }^{1}$ cita del pie del Nevado del Acay y de Chicuana y Luracatao, situadas en las cercanías de La Paya. En otra parte refiere Lozano 2 que en septiembre de 1632, indios del Valle Calchaquí, por consiguiente Diaguitas, «dieron sobre la estancia de un vecino de Salta, distante 7 leguas ( $=56$ kilómetros, por tratarse de leguas coloniales, a 8 kilómetros cada una) de la cindad, y la entraron a saco, matando al dueño y a veinte y seis indios Pulares de su encomienda». Los parientes de estos Pulares muertos convocaron entonces a la gente de todos los pueblos pulares que eran ocho, siguieron a los agresores hasta sus propias viviendas y mataron a gran número de éstos que fueron sorprendidos mientras festejaban su victoria con una gran bacanal. El gobernador Felipe de Albornoz hizo por ello construir el Fuerte de San Bernardo, a seis leguas de Salta, para proteger a los Pulares sumisos a los españoles y amigos de ellos, contra las invasiones de los Diaguitas del Valle Oalchaquí. Es posible que el pueblo de San Bernardo de Díaz, capital del departamento de La Viña, tenga su nombre de ese Fuerte de San Bernardo, pero éste parece haber estado situado más al norte, pues Lozano ${ }^{3}$ Io ubica « en una punta que forman los dos brazos de un río que viene de hacia los Lipes », el cual no puede ser otro que el Río del Toro que pasa cerca de Tinti. Las distancias de Salta a Tinti (35 kilómetros), al Fuerte de San Bernardo (48 kilómetros) y a la estancia donde fueron muertos los veinte y seis Pulares (56 kilómetros), confirman la ubicación del fuerte en la parte sur del Valle de Lerma, y de los datos precedentes resulta que esta parte del valle estaba poblada por Pulares, lo que también está confirmado por la existencia actual de mu lngar poblado cerca de Tinti que lleva el nombre de «Pulares». $\mathrm{Y}$ si los Pulares habitaban el norte del Valle Calchaquí y el sur del Valle de Lerma, es muy natural que también ocuparan la Quebrada de Escoipe y el norte de la Quebrada de Guachipas que forman el camino del

\footnotetext{
${ }^{1}$ Pedro Lozano, Historia de la conquista del Paraguay, Río de la Plata y Tuenmán, tomo V, páginas 61, 160, 213. Ed. Lamas. Buenos Aires, 1873-1875.

: Ibid., tomo IV, páginas $445,458$.

3 Ibid., tomo V, página 147. Aquí dice Lozano que el Fuerte de San Bernardo distaba s6lo tres leguas de Salta, mientras que en el tomo IV, página 458, da la distancia como de seis leguas. Este último dato es seguramente el que ralc, mientras que el otro depende de una equivocación.
} 
Valle Calchaquí al Valle de Lerma, como también lo dice Ricardo Jaimes Freyre ${ }^{1}$ en un libro recién publicado : «Los Pulares se extendían al septentrión (del Valle Calchaquí) y eran especialmente fuertes y numerosos en Guachipas y la Quebrarla de Escoipe ». Los Pulares tomaron parte activa en las gnerras de los «Calchaquíes》 o Diagnitas contra los conquistadores, y siempre figuran en las crónicas de la época como nación propia, separada de los Diaguitas ?.

Al tratar en 1908 de delimitar la región de los Diaguitas de la de los Atacameños, me faltaba material histórico y arqueológico para dar colocación á los Pulares, pero con el material arqueológico ahora reunido no me parece aventurado ubicar el territorio por ellos ocnpado en la forma que acabo de hacer $y$, por otra parte, calificarlos como tribn atacameña, siendo esta calificación apoyada por su nombre que sin duda se deriva del Cerro Pular, pico de la Cordillera que se encuentra inmediatamente al sud del Salar de Atacama.

1 Ricardo Jammes Freyre, El Tucumán del siglo XPI. Publicación de Ia Universidad de Tucumán, página 37. Buenos Aires, 1914. Aunqne el antor no cita el documento del que ha extraído el dato referido es de suponer que proceda de buena fuente por to bien documentado que se ha demostrado en otras ocasiones y porque tiene a su disposición la espléndida colección de documeutos inéditos del Archivo Histórico de Tucumán, institución de reciente creación que se debe a los esfuerzos y el interés por las ciencias del gobernador doctor Ernesto E. Padilla y del rector de la Universidad de Tucumán, doetor Juan B. Terán.

2 Para no hacer otras citas, referiré un párrafo de la carta delle Padri Gio. Ronero e Gasparo di Monroy di Tucuman, publicada en un libro raro: Breve relatione del P. Diego de Torres della Compagnia di Giesù. Procuratore della Provincia del Perì, circa il frutto che si raccoglie con gli Indiani di quel Regno. Dove si raccontano anche alcuni particolari notabili successi gli anni prossimi passati. Per consolatione de i Religiosi di detta Compagnia in Europa. Al fine s'aggiunge la lettcra annua dell' Isole Fillipine del 1600. In Tenetia, MDCIV. Appresso Gio, Battista Ciotti Sanese, All'Aurora, páginas 24-33. (Existen de este libro dos ediciones más, una italiana, auterior, Milán, 1603, y otra francesa : La nouvelle histoire du Pérou d'après la relation du Père Diego de Torres, París, 1604.)

Dan cuenta los PP. Romero y Monroy al P. Torres, procurador de la Compañía de Jesús en la provincia del Perú, de una entrevista que en 1601 tuvieron con unos Diaguitas en el Valle Calchaquí, durante la cual les dice nn viejo curaca diaguita: Noi altri non habbiamo da dismettere le nostre usanze, nè tagliarci $i$ capelli conıe gli altri, y agregan los PP. Romero y Monroy: Questo dissero per $i$ Pulari e Chubani battezzati poco prima, che s'andavano tagliandi li capelli ad imitatione degl' Indiani del Perù, il che tenevano per grau segno, che lasciano la superstitione da vero per attendere alla pietà Christiana...

Este testimonio de los PP. Romero y Monroy, en cuanto a la difcrencia entre Diaguitas $y$ Pulares, es importante, pues conocían a foudo estos pueblos, entre los cuales obraran como misioneros. 
Fueron los descubrimientos de Ambrosetti en La Paya los que primero ${ }^{1}$ me indujeron a clasificar los Pulares como Atacameños, pues según los documentos históricos ocuparon las región donde está situado este gran pueblo prehispánico, y la mayor parte del material arqueológico allí desenterrado es idéntico o parecido a los objetos dejados por los Atacameños del Desierto de Atacama, Puna de Atacama y Puna de Jujuy. Fuera de este material lian dado las excavaciones en La Paya muchos objetos procedentes de industria y arte diaguitas, y además un número de piezas decididamente peruanas, de la época incaica. Esto demnestra que La Paya, situada justamente sobre el límite de los Diaguitas y de los Pulares atacameños, ha estado poblada por unos y otros, y que allí ha residido durante la ocupación de los Incas alguna autoridad delegada de su imperio.

He tenido la satisfacción de ver mi delimitación geográfica de los Atacameños y mis ideas en cuanto a los Pulares y al pueblo prehistórico de La Paya plenamente aceptadas por Max Uhle ${ }^{2}$ quien en los últimos años ha practicado importantes excavaciones y estudios en el Desierto de Atacama y debe considerarse como el mejor conocedor de la aqueología de esta región.

En cuanto a Tinti, tanto la arqueología como los datos históricos parecen indicar que ha sido un pueblo de Pulares.

${ }^{1}$ E. Boman, Antiquités cit., tomo II, página 778, eu una nota agregada estando la obra ya en prensa.

- Max Uhue, Tabletas de madera de Chiuchiu. Trabajo publicado en la Revista Chilcna de Historia y Geografía, tomo VIII. Tirada aparte, página 3. Sautiago de Chile, 1912. Siendo esta publicación muy difícilmente accesible, creo necesario transcribir los párrafos pertinentes : «Desde que Erie Boman publicó su hermosa obra Antiquités de la région andine, 1908, en que estableció primero, y trató exteusameute, una civilización atacameña de la Puna $y$ del Desierto de Atacama, el candal de esas tabletas para su estudio ha crecido enormemente. La importante obra del señor Ambrosetti sobre la ciudad autigna de La Paya - ciudad atacameña, cono Boman ha establecido con tino - presentó un gran material nuevo para el conocimieuto de esas tabletas y los tubos que casi siempre las acompañan... ${ }^{\prime}$ Las tabletas $\mathrm{y}$ tubos meucionados pertenecen a los objetos más característicos de la arqueología atacameña y existen tanto en los yacimientos prehistóricos del Desierto de Atacama como eu los de la Puna de Jujuy y en La Paya. 

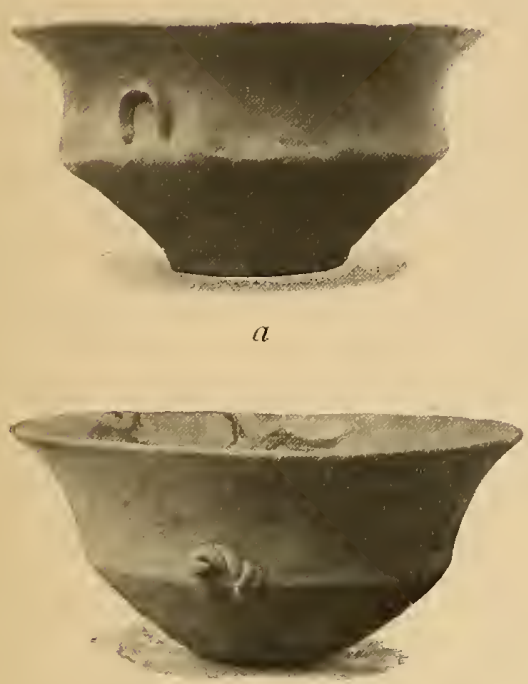

C

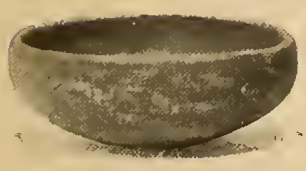

$e$

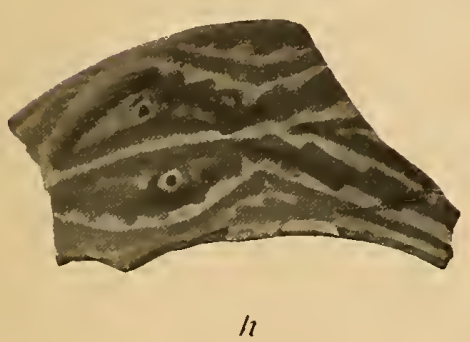

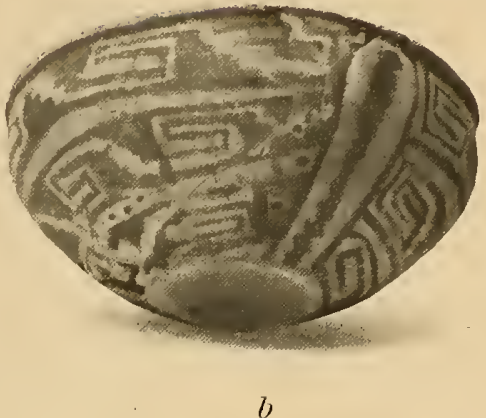

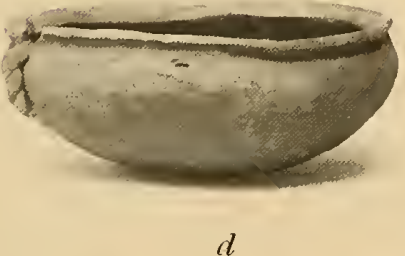

$d$

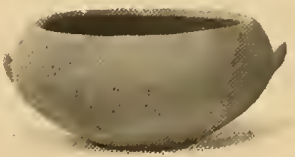

g

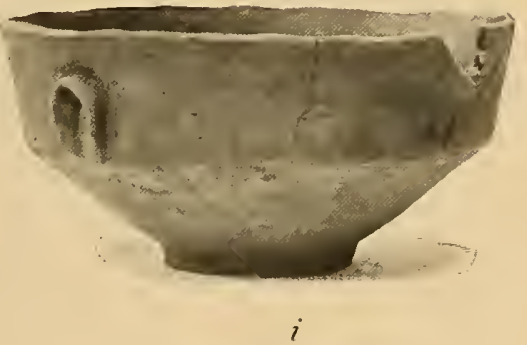

Tinti. Alfarería funeraria. (1/5 del nat.). 


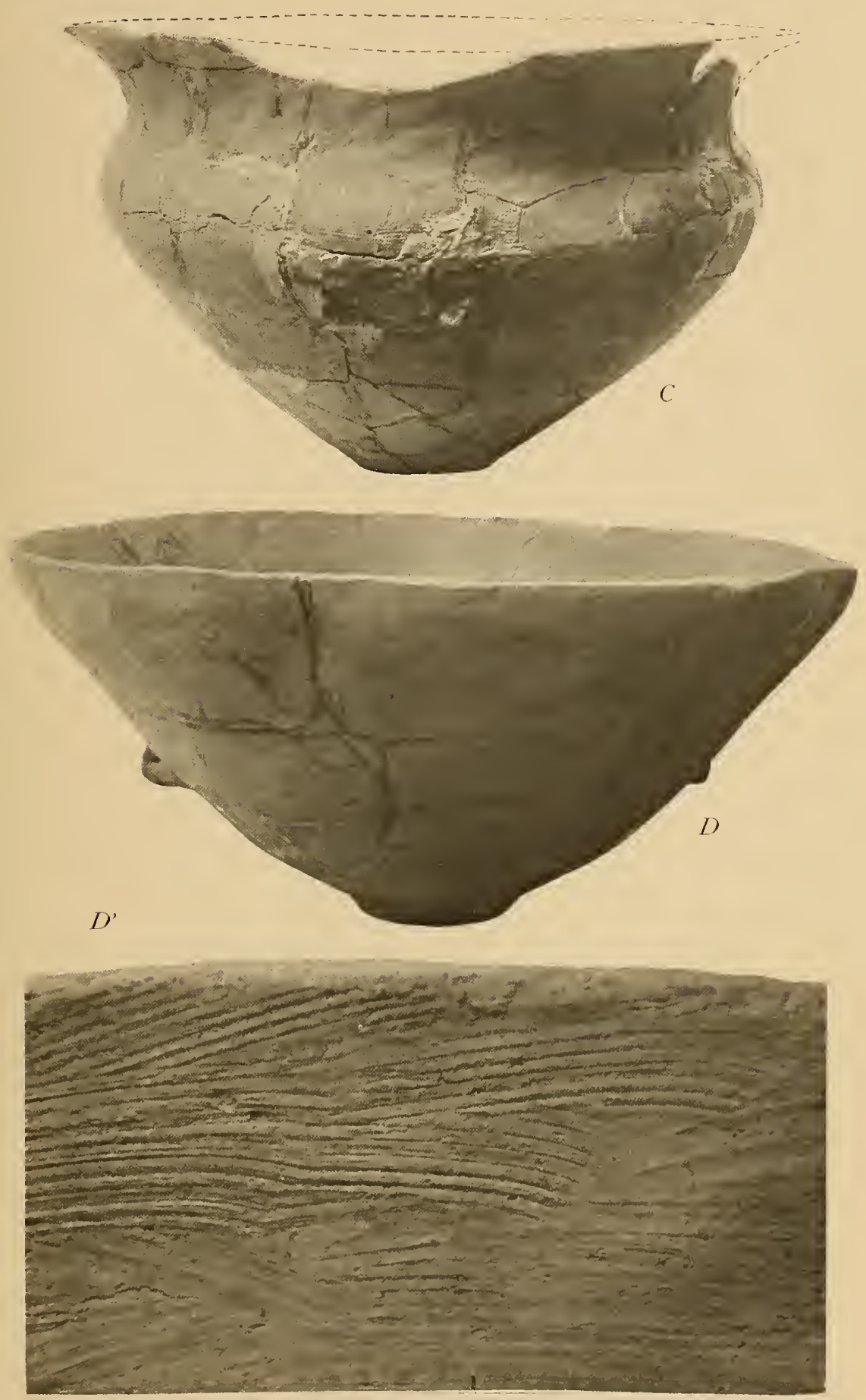

Tinti. $C$ y $D$, Grandes vasijas encontradas en dos construcciones sepulcrales. (1/8 del nat.) $-D^{\prime}$ Fragmento de la superficie interior de la vasija $D$, junto al borde. (1/2 del nat.). 


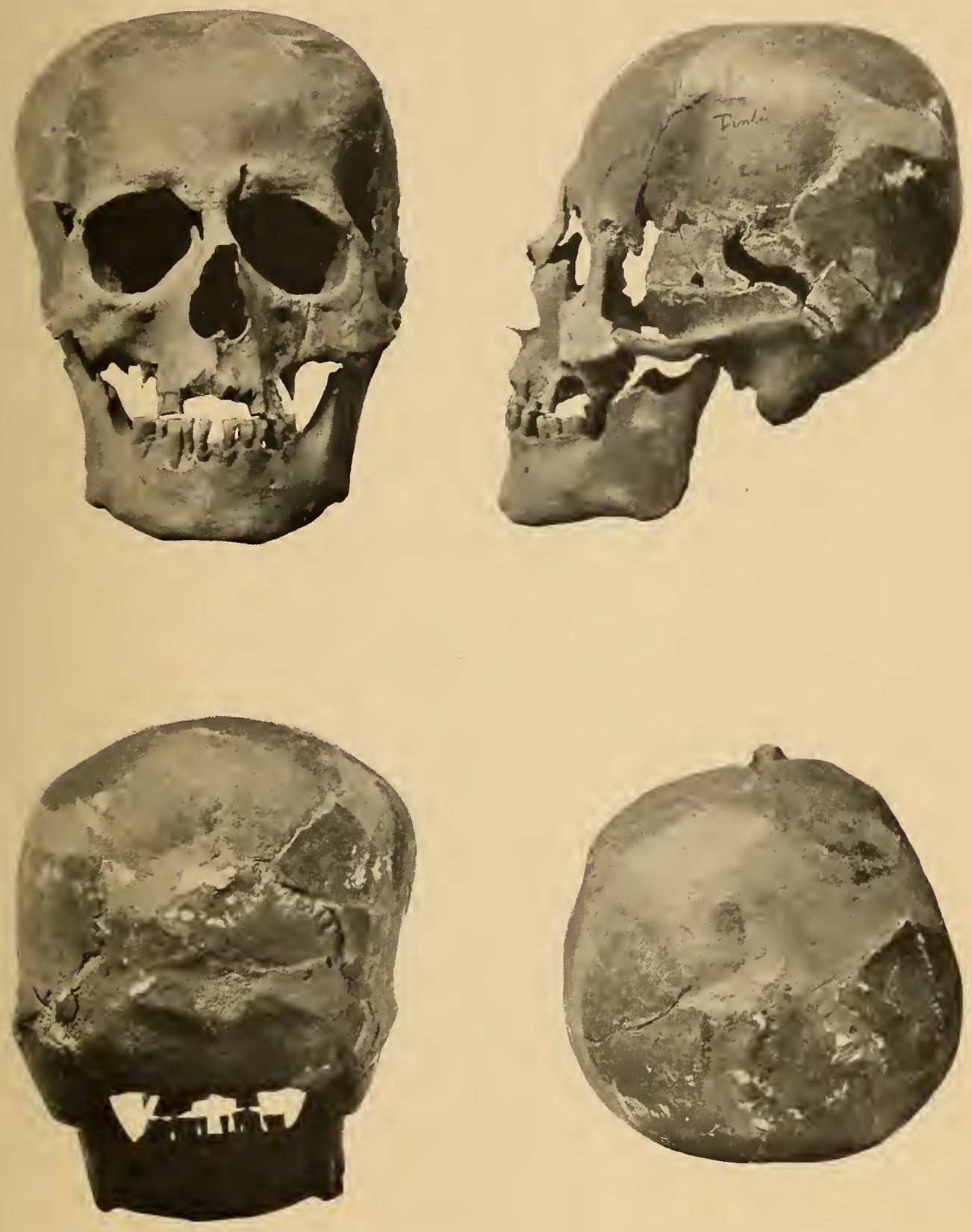

Cráneo procedente de uno de los sepulcros de Tinti. (1/3 del nat.) 


SMITHSONIAN INSTITUTION LIBAARIES

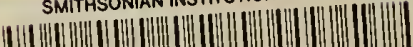

(n) (n) (n)

39088 005861505

Hollinger Corp. pH 8.5 